mechanisms. Chapter 5, by J. D. Bernal, is concerned with molecular biology and with speculations concerning the origin of life. It is not mathematical except implicitly in that the $\mathrm{X}$-ray analysis of proteins involves mathematics. Bernal remarks that biology might become an experimental synthetic science.

In Chapter 6, K. S. Cole shows that the electrical properties of organisms give rise to a good relationship between theory and experiment, with special reference to the squid axon. For example, the successful sodium theory of nerve function propounded by A. L. Hodgkin and A. F. Huxley is dealt with. Much of the mathematical theory here depends on non-linear differential equations. Cole ends the chapter by saying that a reasonably satisfactory model of the membrane seems highly probable in the near future.

G. von Békésy deals with cochlear mechanisms in Chapter 7, and, among other things, points out the importance of neural lateral inhibition. This mechanism occurs again in Chapter 14, by W. Reichardt, in connexion with the eyes of the horseshoe crab Limulus and the beetle Chlorophanus. It is interesting to speculate that lateral inhibition is a fundamental process in the whole hierarchy of the nervous system, and, if so, it is just as important as feed-back.

Chapter 8, by M. S. Bartlett, is concerned with multivariate statistics, and this theory is applied by $\mathbf{R}$. E. Blackith, in Chapter 9, to taxonomic problems. In a wider context, the subject here has been called 'botryology', from the prefix botryo-, a cluster. For the practical use of multivariate methods, a fast computer is necessary. The application of computers is again discussed by $R$. S. Ledley, in connexion with medical diagnosis and the automatic analysis of photographs; and by D. Garfinkel in connexion with the simulation of biochemical and ecological models. Some of what Garfinkel says would apply to economic models also.

In Chapter 12, H. Quastler discusses systems analysis in very general terms, and B. Chance follows with a discussion on chemical mechanisms of metabolic control. In Chapter 15, R. Levins discusses population genetics, and, in the next chapter, R. H. MacArthur writes on ecology from the point of view of natural selection. The book ends with author and subject indexes.

Theoretical biology is a larger subject than can be reasonably well covered in a book of this size, and therefore many of the discussions are superficial or too condensed. Some notable omissions are Turing's work on growth, Moran's on genetics, von Neumann's on selfreplication and Sommerhoff's approach to analytical biology. The book contains references to about six hundred writers, and will be a valuable guide to the literature in spite of the omissions. A useful collateral reference is Mathematics and Computer Science in Biology and Medicine (H.M.S.O., 1965).

I. J. Goop

\section{THE FASCINATION OF THE FUNGAL SPORE}

Spore Liberation

By C. T. Ingold. Pp. ix +210. (Oxford: Clarendon Press; London: Oxford University Press, 1965.) 35s. net.

$\mathrm{O}$ NE might suggest that $S$ pore Liberation helps to give the lie to the belief in two cultures, for it is an elegant, artistic, yet scientifically satisfying production. Prof. Ingold's interest in the liberation and dispersal of fungal spores is well known and this is an epitome of his knowledge and of his experience in many lands.

The chapters are in themselves essay-reviews, at first sight apparently self-sufficient and not connected by a common theme. A second reading shows that they are indeed connected and that the common theme is that "the solution of dispersal problems has had a great impact on the structure of fungi and, therefore, in trying to understand structure its relationship to spore dispersal should be constantly in mind".

The final chapter, on "Spore Liberation in Bryophytes", extends the problem of structure in relation to function to the bryophytes and is useful though slightly out of balance in its scope and coverage.

After a discussion of spore shape in relation to dispersal in the opening chapter, the author considers in detail the mechanisms of spore liberation in the Mucorales. This is an elegant essay, rich in penetrating observations and valuable and little-known detail. The next three chapters form a homogeneous group dealing with spore discharge in Sordaria fimicola, the water relations of spore liberation in terrestrial fungi and the rhythms of spore liberation in fungi. They demonstrate the range of experimentation which can be carried out with simple apparatus in this interesting field. The mode of perception of the light stimulus and the nature of biological rhythms is, however, given a somewhat limited treatment, in part perhaps because of the unsatisfactory state of our knowledge, in general, in these fields.

The next two chapters, the last of those dealing with fungi, are entitled. "Toadstools, their Form and Function" and "Gasteromycetes, or Nature Tries Again". They are essentially speculative, but draw together a great deal of useful information and morphological detail. The treatment is full and well documented, but one is surprised to find no reference to Corner's elaboration of the 'Ampoule effect' of basidia or of his geometrical treatment of the basidiospore spacings.

But there is little to criticize in this excellent production; beautifully written and very well illustrated, it sustained my interest from cover to cover, taught me many things and stimulated me to go and look again at fungi in the field and the laboratory. Can we ask much more of an author?

N. F. ROBERTSON

\section{ENERGY EXCHANGE IN FARM ANIMALS}

\section{Energy Metabolism}

Proceedings of the Third Symposium held at Troon, Scotland, May 1964. Edited by K. L. Blaxter. (European Association for Animal Production Publication No. 11.) Pp. xiv +450. (London: Academic Press, Inc. (London), Ltd.; New York: Academic Press, Inc., 1965.) 958 .

F NERGY Metabolism consists of the texts and dis$E$ cussions of the forty-one papers presented at the third symposium on energy metabolism held in 1964. Its title is rather misleading since the majority of the papers are confined to studies of energy exchange in farm animals. Considerable emphasis is given to such fields as the energy value of feeds and effects of environmental changes on onergy metabolism, while the more fundamental aspects of the subject are poorly represented. As an indication of present-day views and ideas the symposium is a little disappointing. The discussions following individual papers are generally brief or even absent, and there is a tendency to present experimental material without attempting to interpret its significance or relate it to other work in the field. A fow papers would appear to have suffered from a too literal translation from their original language, and since some were apparently read untranslated this may in part explain the lack of discussion.

The symposium opened with an inaugural address by Sir Hans Krebs on general aspects of gluconeogenesis and ketogenesis. The book is then divided into eight sections beginning with a rather heterogeneous series of papers collected under the general heading of physiological and 